\title{
THE BENEFITS AND CHALLENGES OF HAVING AN OPEN AND FREE BASIS SATELLITE DATA SHARING PLATFORM IN TURKEY: GEZGIN
}

\author{
Hüsne Seda Deveci, Aziz Koru, Ufuk Sakarya, İsmail Tevrizoğlu, Mustafa Teke, Ramazan Küpçü, Bülent Avenoğlu, Can \\ Demirkesen, Sevgi Zübeyde Gürbüz, A. Feray Öztoprak, İbrahim Serdar Açıkgöz, İsmail Hakkı Demirhan, Ali Ömer Kozal, \\ Mehmet Efendioğlu, Erdinç Berke, F. Fehmi Şimşek, İlkay Atıl, Derya Kaya, Pınar Uçmak, Eda Ersöz, Hilal Özen
}

TÜBİTAK UZAY (The Scientific and Technological Research Council of Turkey, Space Technologies Research Institute), ODTÜ Yerleşkesi, 06800, Ankara, Turkey - (seda.deveci, aziz.koru, ufuk.sakarya, ismail.tevrizoglu, mustafa.teke, ramazan.kupcu, bulent.avenoglu, can.demirkesen, sevgi.gurbuz, feray.oztoprak, ibrahim.acikgoz, hakki.demirhan, omer.kozal, mehmet.efendioglu, erdinc.berke, fehmi.simsek, ilkay.atil, derya.kaya, pinar.ucmak, eda.ersoz, hilal.ozen)@ tubitak.gov.tr

$$
\text { SpS7 - GEO }
$$

KEY WORDS: RASAT, GEZGIN, Satellite data sharing platform

\begin{abstract}
:
Turkey is a county that experiences rapid socioeconomic development, which, in turn, leads to high urbanization rates due to migration of people from rural to urban areas, many large-scale development projects (e.g. highways, dams, housing and infrastructure), and environmental problems that adversely affect agriculture, such as soil erosion and deforestation. Furthermore, Turkey lies in a region prone to natural disasters, especially earthquakes, landslides, flooding and forest fires. Successfully overcoming these challenges requires continuous monitoring to enable rapid response as well as the development of effective socioeconomic policies. In this regard, space-based earth observation (EO) systems play a critical role in the rapid acquisiton and extraction of crucial information. The first launch of the first Turkish-designed satellite, RASAT, in 2011 led to the wide-spread exploitation of space-based resources by Turkish institutions through the dissemination of EO data on an open and free basis via the GEZGIN internet portal (http://www.gezgin.gov.tr). The push for data sharing was further instigated by the nationally funded project GEOPORTAL ("Satellite Image Processing and Geoportal Development Project") and European Union FP7 project EOPOWER ("Earth Observation for Economic Empowerment"), which strove to create conditions for sustainable economic development through the increased use of Earth observation products and services for environmental applications. In this work, the technical challenges involving processing and preparing raw satellite data for dissemination as well as software design of the GEZGIN Portal will be presented.
\end{abstract}

\section{INTRODUCTION}

With the launch of the Turkey's first nationally designed satellite, RASAT on August 27, 2011 (Kahraman et al. 2012), and a higher resolution earth observation satellite, Göktürk-2, on December 18,2012 , (Iş1k et al. 2015) wide-spread exploitation of spacebased resources by Turkish institutions became possible for the first time. Still operational, RASAT has provided imagery from various parts of the entire world covering approximately $10,500,000 \mathrm{sq}$. km. The RASAT satellite has a resolution of 7.5 meters panchromatic and 15 meters RGB, where Göktürk-2 has a resolution of 2.5 meters panchromatic and 5 meters for RGB and NIR.

To fully take advantage of this data, a means for quick and effective dissemination was required. This led to the initiation of a project funded by the Turkish Ministry of Development called GEOPORTAL ("Satellite Image Processing and Geoportal Development Project") and subsequent participation in the European Union funded project EOPOWER ("Earth Observation for Economic Empowerment"), which strove to create conditions for sustainable economic development through the increased use of Earth observation products and services for environmental applications.

In this work, the design and development of the imagery data sharing platform, GEZGIN, is described in detail, along with the automated image processing algorithms incorporated into the software. The contribution of the GEZGIN platform to the socioeconomic development of Turkey and, on a regional-scale, to Europe is also discussed.

\section{GEOPORTAL PROJECT}

After the launch of RASAT, the need for an easy, practical way to enable potential users to access satellite imagery became apparent. To address this need, a portal that would distribute processed images freely to Turkish academy and organizations was envisioned. RASAT imagery may be used for various civil applications on mapping and planning, land cover/use, disaster management, ecosystem monitoring, environmental control, forestry, agriculture, survey and coastal zone management for urban regional planning, and similar other purposes. To provide raw and processed RASAT images to potential end-users, some services have been provided, such as the geometric and radiometric calibration of data, as well as the generation of mosaic imagery of Turkey - all through a web interface. A project called "Satellite Image Processing and Geoportal Development Project (GEOPORTAL)" was initiated with the financial support of the Turkish Ministry of Development. The GEOPORTAL Project was officially started at January, 2013. On 24 January, 2014, the GEOPORTAL project also achieved certification at CMMI Level 3, the most widely implemented process improvement approach in the world.

Under the auspices of the GEOPORTAL Project, the

- Geometric calibration,

- Absolute and relative radiometric calibration,

- Mosaic imagery, and

- Access via a web interface (geoportal), complete with underlying database, metadata, catalogue, and search capabilities, 
of the raw satellite imagery acquired from the RASAT satellite is provided as a service to end users.

RASAT, capable of acquiring 7.5-meter resolution panchromatic imagery as well as 15-meter resolution color RGB imagery from any place on the world, sends the imagery it takes to the TUBITAK UZAY ground station located in Ankara, Turkey. The raw images (Level-0/L0) downloaded to the ground station are then processed with automatic image processing software developed by TUBITAK UZAY engineers before being provided to the end users at multiple data levels. Level-0 is the system product that corresponds to raw compressed data in which the radiometric defects of raw images (such as striping) are corrected. In Level-1 processing, radiometric correction, band registration, Modulation Transfer Function (MTF) sharpening processes are executed. After geo-referencing in Level-2, orthorectification with Shuttle Radar Topography Mission (SRTM) Digital Elevation Model (DEM) is performed in Level-3 processing.

In the scope of this project, Turkey's first national satellite imagery portal called the GEZGIN Portal was developed to facilitate sharing of earth observation satellite imagery over the internet. GEZGIN is based on sharing RASAT satellite images and taking new requests over the internet. The raw imagery obtained from the RASAT satellite are uploaded to the GEZGIN portal (www.gezgin.gov.tr) after geometric and radiometric correction followed by coordinate registration.

Turkish citizens may download desired RASAT imagery free of charge, as well as request the acquisition of new imagery, through the e-Government Gateway (e-Devlet Kap1s1) web interface since November, 2015. The e-Government Gateway is a website offering access to a variety of public services through a single, unified secure login website. Currently, only Turkish Citizens are able to benefit from GEZGIN Portal through the e-Government Gateway (Figure 1, left).

Through the GEZGIN Portal, desired imagery may be easily downloaded by searching through defined borders, place name, coordinates, or uploading a document (shp or $\mathrm{kml} / \mathrm{kmz}$ format).

Since GEZGIN's inception and debut on 19 August 2014, GEZGIN has hosted almost 7500 RASAT images, and has had over 190,000 visitors, of which 7192 members downloaded 9560 images as of April, 2016.
Transitioning to the e-Government system for automatic login and retrieval of imagery resulted in a five-fold increase in the number of site members and two-fold increase in the amount of data downloaded within just a four month period of time, as may be seen from the bar chart of user statistics given in Figure 1(right).

- Usage statistics as of the end of November 2015:

$>1601$ members

> 4230 RASAT images downloaded by members.

$>\quad 140,000$ total visitors (approx. 9300 monthly).

- $\quad$ Usage statistics for November 2015 - March 2016:

> 7192 new members registered and old memberships have been cancelled.

> 5330 RASAT images downloaded by members.

> 52,000 visitors (approx. 13000 monthly).

Although currently only RASAT imagery is accessible and downloaded through GEZGIN, since 2015, select imagery from both RASAT and Göktürk-2 that have been taken from all over the world have been shared via GEZGIN BLOG (blog.gezgin.gov.tr), as pictured in Figure 2.

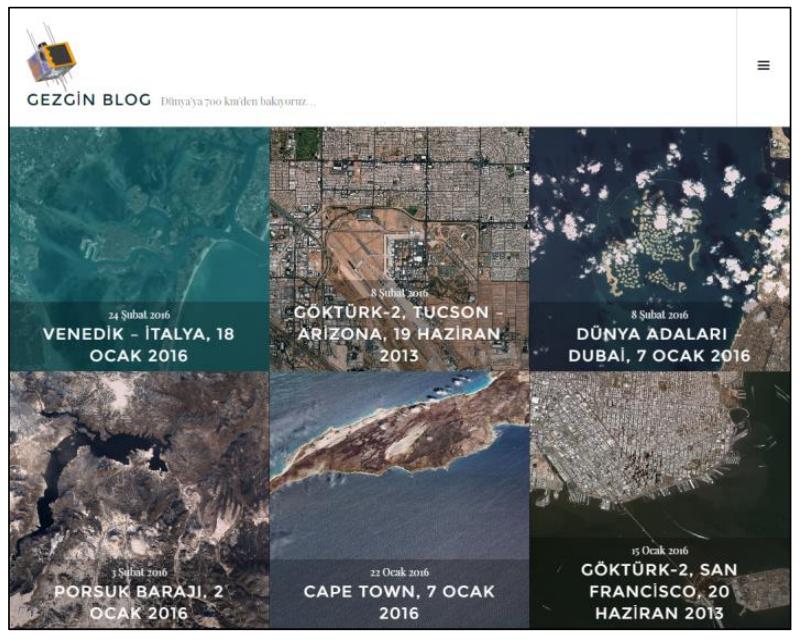

Figure 2. Sample images shared through GEZGIN Blog.
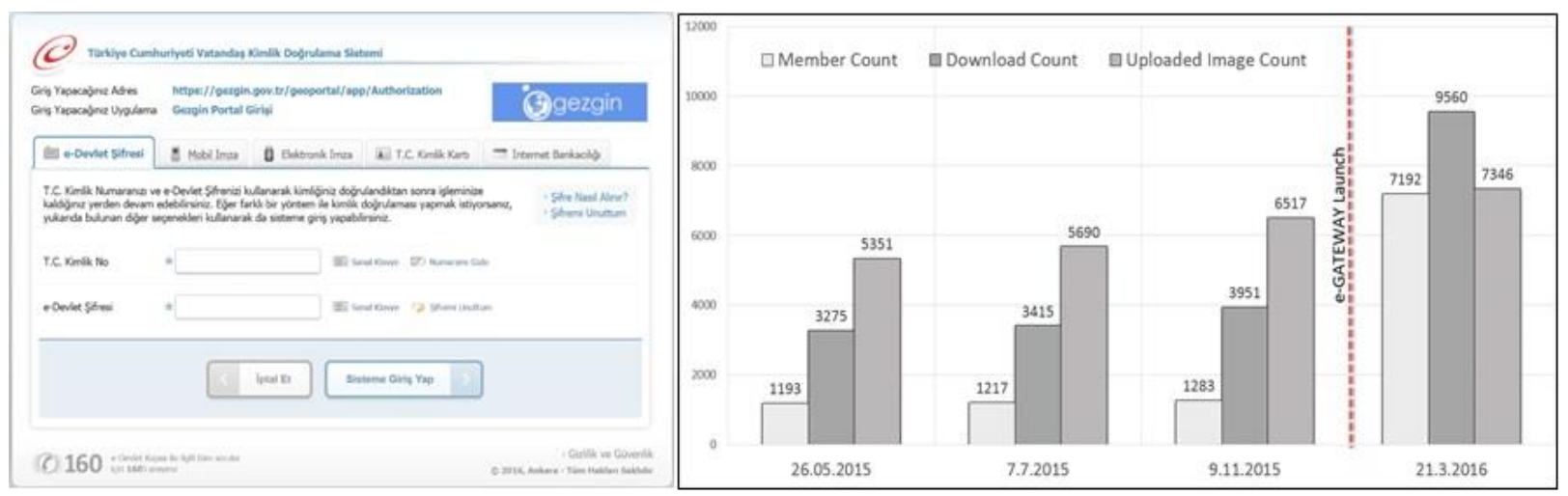

Figure 1. GEZGIN Portal e-Government login screen (left) and user statistics (right). 


\section{RASAT IMAGE PROCESSING CHAIN}

TUBITAK UZAY has developed its own automatic satellite image processing suite, VI (Veri Işleme/Data Processing) software. RASAT images are processed with minimal user interaction. Automation also decreases the amount of processing errors and processing time. The image processing work package of GEOPORTAL project is comprised of all related satellite imagery functions (Figure 3). Sub-packages in the work package are Data Generation and Management, Radiometric Calibration, Geometric Calibration and Data Processing.

Raw data is processed based on the modules in the work package. RASAT Imagery Levels (Teke, 2016) are depicted in Figure 4. Satellite data is processed from raw data (L0) to other levels. In L0 step, radiometric correction is applied by using response and offset values of each pixel to normalize sensor response. Response and offset values are obtained through a relative radiometric calibration process (Teke et al. 2016). MTF sharpening is applied to minimize motion blurring and obtain Level 1 data. Band registration is performed to obtain L1R level by registering multispectral bands to panchromatic bands. Flares in L1R RASAT imagery are corrected and saturation in red band is normalized. After these operations, the cloud cover ratio is computed to produce L1RB level data. In L2 level, georeferencing is performed using Landsat 8 imagery. A mosaic is created by automatically routing the most recent 2013 and 2014 Landsat 8 imagery through cloud servers and georeferencing the imagery through specially developed software. SRTM 90m DEM is used for orthorectification in L3 step.

In addition to these standard data levels, the GEZGIN Portal also provides the option of obtaining pansharpened imagery. Based upon work comparing a variety of pansharpening algorithms on RASAT imagery (Teke et al. 2014), it was found that the Hyperspherical Color Sharpening (HCS) algorithm yielded the best results. An example of the RASAT pansharpening process is given in Figure 5. Image colors have been enhanced using adaptive histogram equalization and unsharp masking to yield the final product.

Moreover, imagery may be selected from a mosaic image of Turkey that is generated by choosing low cloud ratio and similar colored images of the years 2012, 2013 and 2014. ENVI 5.2 software was used to first form 30 smaller mosaics of about 100 frames, before combining to construct the entire mosaic of
Turkey, shown in Figure 6. The entire mosaic may be downloaded through the GEZGIN Portal for different selections of image size and resolution.

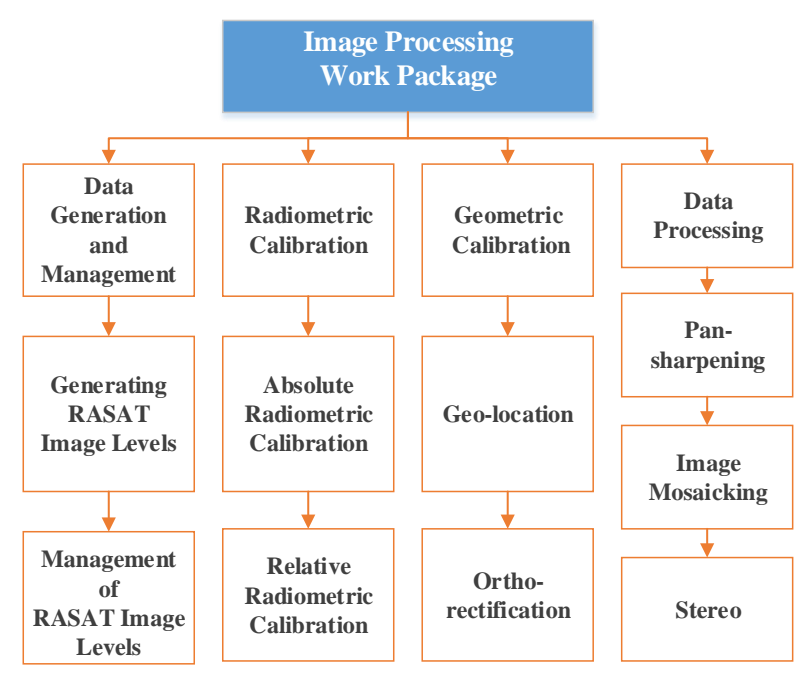

Figure 3. Image Processing Work Package

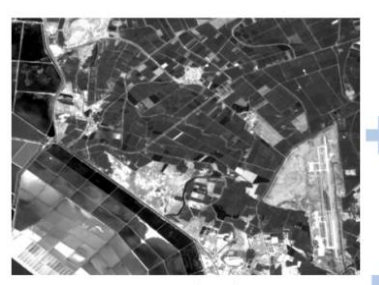

Izmir (Pan)

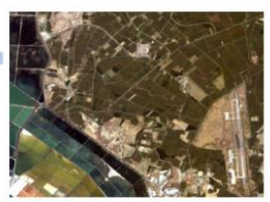

Izmir (RGB)

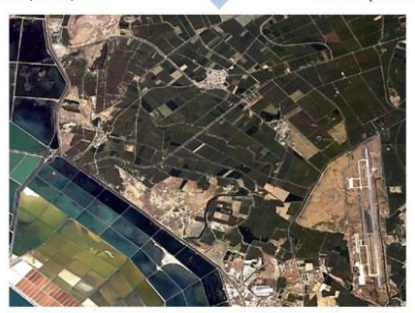

Izmir (Pansharpened)

Figure 5. RASAT Imagery Panharpening Process

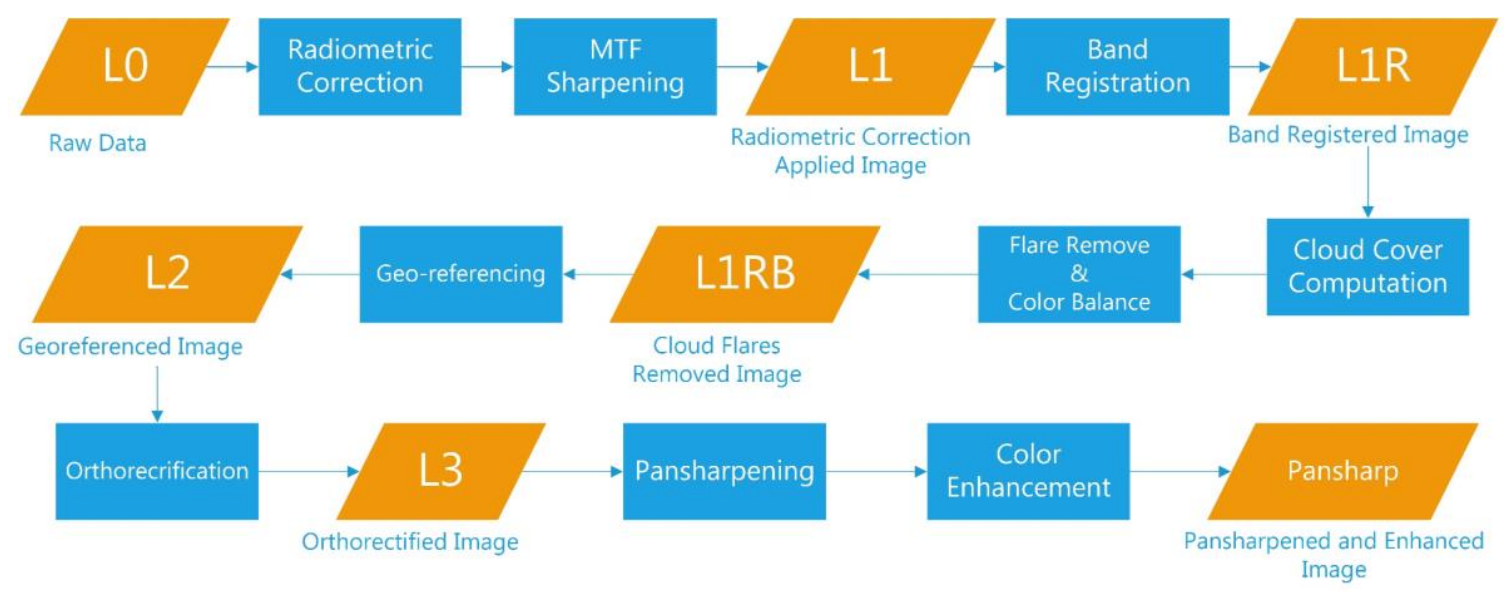

Figure 4. Image Processing Chain 


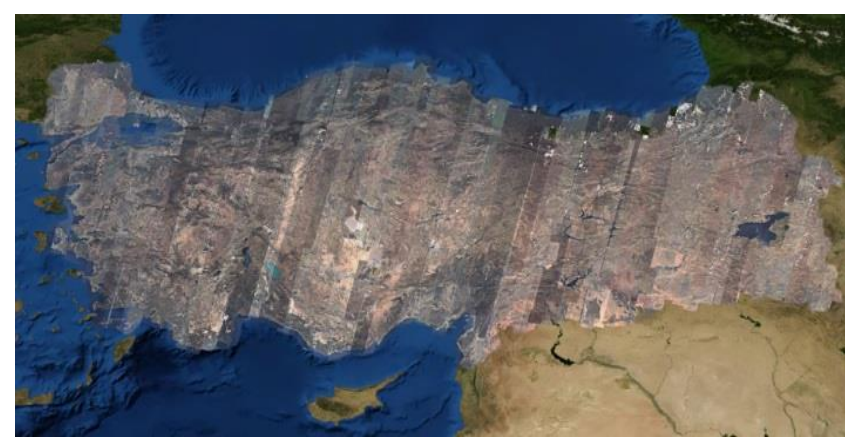

Figure 6. Mosaic image of Turkey.

\section{TUZ GOLU RADIOMETRIC CALIBRATION CAMPAIGN}

Radiometric calibration is essential to ensuring the quality of data obtained from space assets as well as the inter-operability of data obtained from different satellites, especially for earth observation applications. The pixel values of an image are related to the radiance of a scene on the earth's surface after going through a number of transformations. The top-of-atmosphere (ToA) radiance measured by a space-borne sensor is the sum of a number of radiance sources, including direct solar radiation reflected from the ground to the sensor, scattered, direct and indirect reflections, as well as upwelled radiance scattered from the atmosphere to the sensor. Meaningful interpretation of satellite data requires relating the surface radiance to the ToA radiance, as well as characterization of the sensor to account for any distortion due to the satellite optics, detector and electronics that may occur during the process of forming the satellite image. It is only through radiometric calibration - a calibration of the measurements relating to electromagnetic radiation at all wavelengths - that pixel values of an image can be related to physically meaningful quantities, consistent with measurements of other satellites (Teke et al. 2015).

The absolute radiometric calibration of RASAT and Göktürk-2 satellites is accomplished through field measurements taken at Tuz Golu, an endorheic Salt Lake located in Central Turkey. Through studies conducted via an ESA-funded project, Comparisons to Maintain Traceability for Optical Sensors (CONTROLS), Tuz Gölü was found to have exceptional qualities and was thus selected by the Committee of Earth Observation Satellites (CEOS) as a LANDNET site (Gürol et al. 2010, Gürbüz et al. 2012).

During the field campaigns, ground measurements are taken using a sun photometer, weather station and spectrometer on the days prior to and same day as the overpass of satellites. Four $3 \mathrm{x}$ 50 meter tarpaulins are placed along the flight direction of Göktürk-2 to serve as an MTF target, with location determined by digital GPS and visible by the satellite, as shown in Figure 7. Details of the radiometric calibration process have been published in a variety of international journals and conferences (Gürol et al. 2008, Gürol et al. 2010, Gürbüz et al. 2012, Teke et al. 2016). Cross calibration and relative calibration of RASAT and Göktürk can be found in (Teke et al. 2016).

Unmanned aerial systems (UAS) are gaining attention in the field of remote sensing. Compared with more traditional aircraft or satellite based platforms, UASs provide several advantages. Their low operating altitude enables to generate data with a high spatial resolution, especially in small inaccessible areas or in harmful sites. Moreover, short re-visit times relative to satellite platforms and reduced preparation time of UAVs compared with airborne systems makes UASs versatile tools for data acquisition.
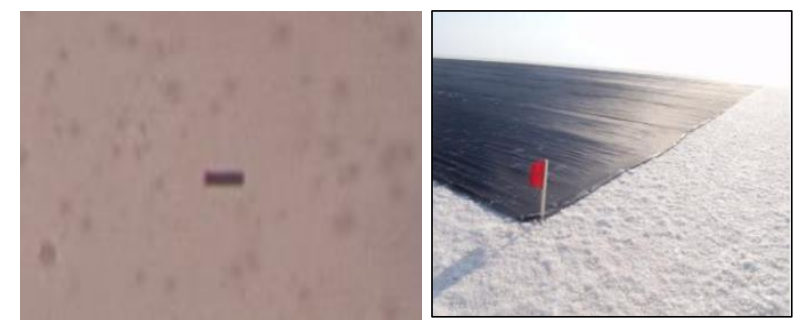

Figure 7. Tarpaulins as seen in Göktürk-2 images (left). Same tarpaulins as seen from the ground (right).

In the most recent 2015 field campaign, ground measurements were augmented by airborne measurements taken under 100 meters from the ground by an unmanned octocopter (drone) equipped with a hyperspectral camera. Drone system consist of Height Tech HT- 8 octocopter and Cubert UHD 185 hyperspectral camera. Overall system can be seen in Figure 8.

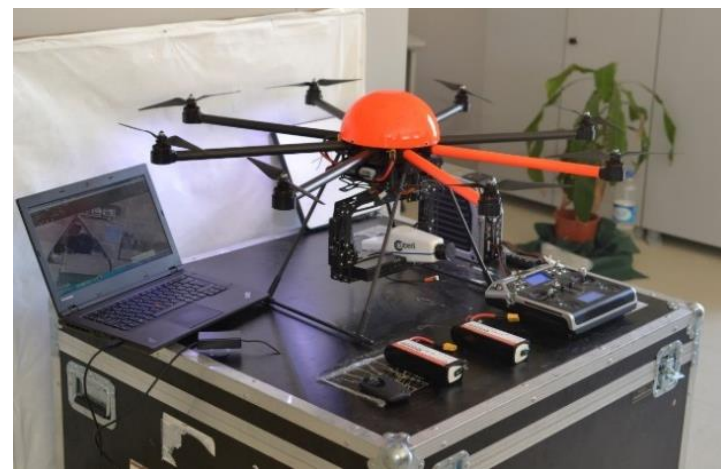

Figure 8. Octocopter with mounted hyperspectral camera

The camera has $450 \mathrm{~nm}-950 \mathrm{~nm}$ wavelength range and capable of $4 \mathrm{~nm}$ spectral resolution sampling that gives us 125 band for each image. Swath width is about $25 \mathrm{~m}$ for $100 \mathrm{~m}$ flight altitude and zero nadir angle. Ground Sample Distance (GSD) has been measured $46 \mathrm{~cm}$ for 13 degree camera lens. Flight time has been set right after the satellite completed its imaging operation and $70 \mathrm{~m} \times 210 \mathrm{~m}$ area has scanned in grid pattern within 12 minutes flight where each flight had $\% 20$ side overlap and $\% 70$ frontal overlap. Detailed flight route can be seen in Figure 9. A paper on radiometric calibration relating UAS data is still being worked and will be published later.

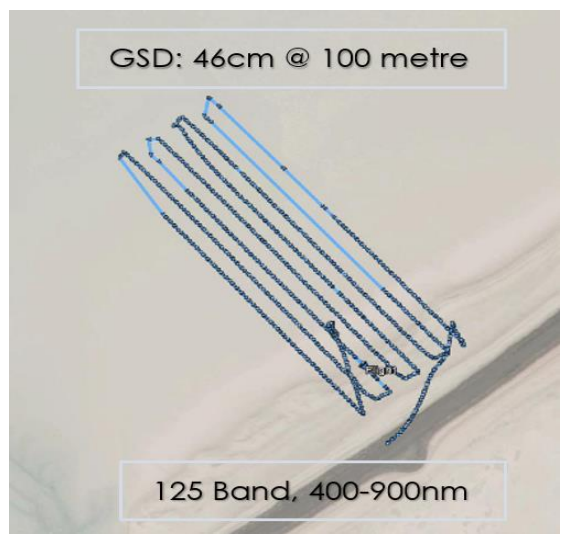

Figure 9. Study site Tuz Golu and route of our Unmanned Aerial System (UAS) 


\section{GEZGIN PORTAL DESIGN}

Various levels of RASAT image products are made publically available through the GEZGIN GeoPortal, located at http://www.gezgin.gov.tr. The GEZGIN portal enables users to:

- Search worldwide RASAT images by selecting political boundaries, uploading files (.shp, .kml and .kmz), drawing a map or entering coordinates. Search results may be filtered according to parameters such as the date or degree of cloudiness present in the image.

- Preview images retrieved by the search engine and view information about the image, such as acquisition date, cloud coverage ratio, elevation angle, frame number, and image dimension in pixels (row vs. column).

- Download the selected images through login via the eDevlet (e-Government) identity authentication system.

- Request the acquisition of new RASAT imagery through an online request form.

Several important challenges must be taken into account during the design of a data sharing platform, such as GEZGIN; namely, 1) sustainability - i.e., ease of keeping information up to data and compatible with archived data, 2) user-friendliness - i.e., simplicity and ease of navigation without external support, 3) security - i.e., data security and enforcement of authorizations in accordance to TUBITAK UZAY data sharing policies, and 4) performance - i.e., uploading speed and computational efficiency.

The GEZGIN software infrastructure is designed with the aim of maximizing efficiency and performance, as defined above. Tools used to develop the GEZGIN portal include:

- GeoServer: an open source Java server that allows users to share, process and edit geospatial data

- Eclipse: compiler for Java code development

- Hibernate: an object-relational mapping framework for Java

- Spring Application Framework: programming and configuration model for Java-based application development
- $\quad$ Spring Security Framework: authentication and access control framework to implement user login and ensure data security

- PrimeFaces: framework for user interface design

- OpenLayers: a javascript library to load, display and render maps from multiple sources on web pages

The GEZGIN system architecture is comprised of seven main modules (Figure 10):

- User Module: defines user authorizations and executes user requests. Users are required to state their name, citizenship number, organizational affiliation, position, e-mail address and telephone number.

- Web Map Service (WMS) Module: provides RASAT images and vector data for user processing and editing.

- Search Module: searches the WMS based upon parameters given by user.

- $\quad$ Archive Listing Module: lists search results based on user inputs and filter settings, and provides image details and geospatial placement on a map

- Map Module: enables users to view and manipulate images comprising mosaic image of Turkey. Images may be filtered according to year and selected from an interactive map showing place names, urban structures, and roads.

- $\quad$ Download Module: enables users to download selected images (L1, L1R, L1RB, L2, RGB, Pansharp, Vector) upon login via e-Devlet (e-Government) identity authentication system.

- Request Module: enables users to request the acquisition of new RASAT imagery. As part of the request, users are asked to state the degree of urgency, coordinates, time frame for acquisiton, maximum permissable cloud ratio and elevation angle, and purpose for request (application for which the images will be used). Requests are evaluated by a system operator and forwarded to mission planning if the request is approved. The status of imagery request may be followed from interactive user menu accessible upon login.

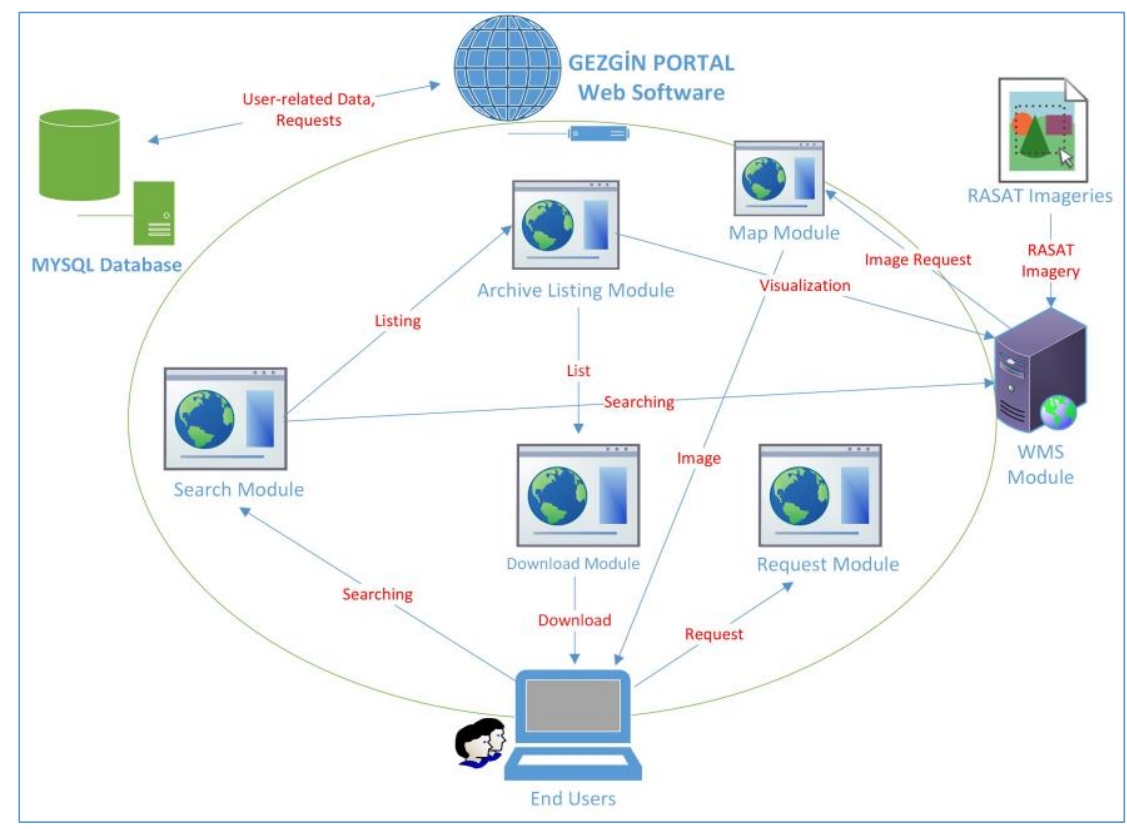

Figure 10. GEZGIN system architechture. 


\section{EUROPEAN-WIDE DATA SHARING}

The successes of the GEOPORTAL Project also contributed to European-side efforts in data sharing through the 7th Framework Programme funded EOPOWER project: Earth Observation for Economic Empowerment (EOPOWER Project, reference:603500). The goal of EOPOWER (http://www.eopower.eu/) is to create conditions for sustainable economic development through the increased use of Earth observation products and services for environmental applications. This purpose serves the higher goal of effective use of Earth observation for decision making and management of economic and sustainable development processes. The marketing instruments applied to achieve this purpose are promotion, capacity building, and science valorization.

The TUBITAK Space Technologies Research Institute (UZAY) is an active participant and partner in the EOPOWER project and is responsible for Work Package 9 - empowering economic development in Turkey and Turkish-speaking countries. This task also builds on other regional earth observation capacity building projects, such as GEONetCab, BalkanGEONet, OBSERVE, EnviroGRIDS, SEOCA and EGIDA. These projects included efforts on producing global and regional marketing studies, success stories, marketing toolkits and valuable feedback from promotion activities and quick-win projects. EOPOWER was a direct benefactor of such experience.

Having all these in mind TUBITAK UZAY's responsibilities towards EOPOWER project lies on Group on Earth Observations (GEO) and Copernicus - the European Earth Observation Programme's data and information policy. Group on Earth Observations (GEO) recognizes that the societal benefits arising from Earth observations can only be fully achieved through the sharing of data, information, knowledge, products and services. Objectives of the data and information policy of Copernicus are to promote the use and sharing of Copernicus data and information; to strengthen Earth observation markets in Europe, in particular the downstream sector, with a view to enabling growth and job creation; to support the European research, technology and innovation communities.

As the primary goal of EOPOWER is economic development, the focus of the project is on impact assessment of project activities and on impact assessment of a selected number of earth observation solutions. In this context, the GEZGIN Portal was selected to address the responses given by the end user community in Turkey. A major success of the GEZGIN Portal has been its role as a catalyst for the use of earth observation data for precision agriculture in Southeastern Turkey - an ongoing project that shows promise for increasing agricultural productivity.

Another example of the use of RASAT imagery is urban development and planning; for example, construction projects can be monitored from space. Figure 11 shows the changes in the Bosphorus Strait region due to the construction of the Yavuz Sultan Selim Bridge.

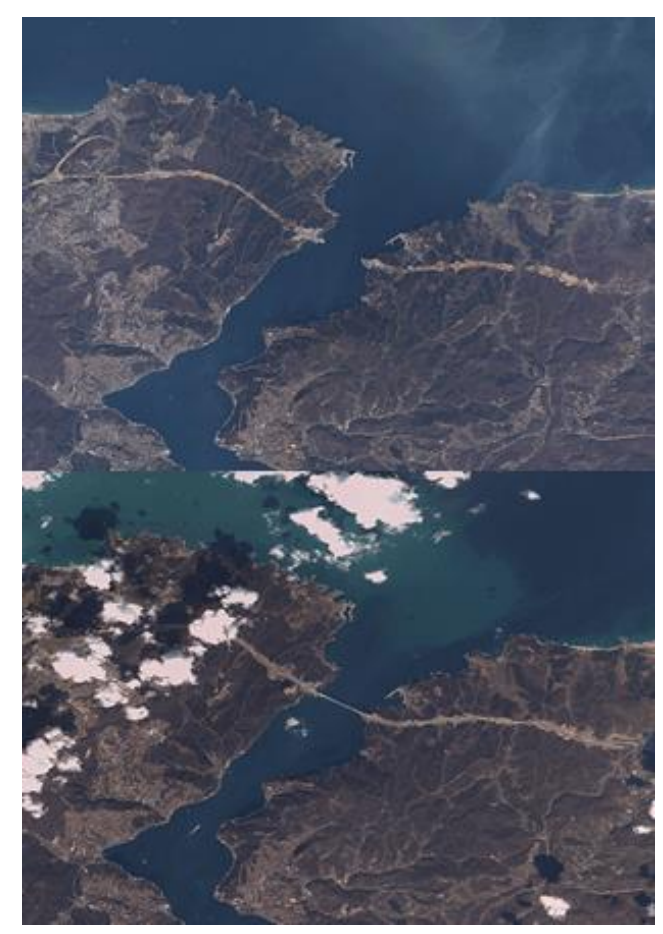

Figure 11. RASAT imagery showing construction of Yavuz Sultan Selim Bridge over the Bosphorus, (top) before construction began in 2014 and (bottom) current state of construction in 2016 .

\section{CONCLUSION}

Data sharing is a critical use of information technologies to enable wide-spread use of earth observation data. In many areas of applications, satellite data may be used to improve planning, development and productivity, thereby yielding a significant contribution to socio-economic development. In Turkey, during the several years that the GEZGIN data sharing portal has been in service, a significant increase in users of satellite data, and projects exploiting satellite data has been observed. A main example is that remote sensing data has recently begun to be used for precision agriculture in Southeast Turkey and urban monitoring in Istanbul.

\section{ACKNOWLEDGEMENTS}

This work is supported by Ministry of Development under funding of Satellite Image Processing Center and Geoportal Development Project.

Authors would like to thank Turkish Air Force for providing Göktürk-2 satellite imagery.

\section{REFERENCES}

EOPOWER Project: Earth Observation for Economic Empowerment, reference: 603500, Funded under: EU FP7ENVIRONMENT.

Gürbüz, S. Z., Özen, H., and Chander, G., 2012. A Survey of Landnet Sites Focusing on Tuz Golu (Salt Lake), Turkey. International Archives of the Photogrammetry, Australia, Remote Sensing and Spatial Information Sciences, 39, B1. 
Gürol, S., Behnert, I., Özen, H., et. al., 2010. Tuz Gölü: new CEOS reference standard test site for infrared visible optical sensors. Canadian J. Rem. Sens., Vol. 36, No. 5, pp. 553-565.

Gürol, S., Özen, H., Leloğlu U., and Tunalı E., 2008."Tuz Gölü: New absolute radiometric calibration test site," ISPRS Congress, Beijing, China.

Işık, N., Avenoğlu, B., İmre, S. E., Açıkgöz, I. S., \& Eroğlu, M., 2015, June. UzayMP: Modular mission planning tool for earth observation satellites with imaging payload. In Recent Advances in Space Technologies (RAST), 2015 7th International Conference on (pp. 449-454). IEEE.

Kahraman, Ö., Özen, H., Demircioğlu, E., Sakarya, U., Küpçü, R., Avenoğlu, B., İmre, E., Bank, E., 2012. Uzaktan algilamada RASAT: Türkiye'de üretilen ilk yer gözlem uydusu (RASAT in remote sensing: First earth observation satellite built in Turkey)," in IV. Uzaktan Algılama ve Coğrafi Bilgi Sistemleri Sempozyumu (UZAL-CBS 2012), Zonguldak.

Teke, M., 2016. Satellite Image Processing Workflow for RASAT and Göktürk-2, Journal of Aeronautics and Space Technologies, 9(1).

Teke, M., Demirkesen, C., Haliloğlu, O., İmre, E., 2016. Göktürk-2 Uydusunun Bağıl ve Mutlak Çapraz Radyometrik Kalibrasyonu (Relative and Absolute Cross Radiometric Calibration of Göktürk-2 Satellite), Harita Dergisi, 155.

Teke, M., Seyfioğlu, S., Ağçal, A., Gürbüz, S., 2014. Optimal Pansharpening of RASAT Satellite Imagery, in Signal Processing and Communications Applications Conference (SIU), $201422^{\text {nd }}$.

Teke, M., Tevrizoğlu, T., Öztoprak, A., Demirkesen, C., Açıkgöz, İ., Gürbüz, S., Küpcü, R., Avenoğlu, B., GEOPORTAL: TÜBİTAK UZAY Satellite Data Processing and Sharing System," in Recent Advances in Space Technologies (RAST), 2015 7th International Conference on, 2015. 